\title{
Leptin Selectively Decreases Visceral Adiposity and Enhances Insulin Action
}

\author{
Nir Barzilai, Jiali Wang, Duna Massilon, Patricia Vuguin, Meredith Hawkins, and Luciano Rossetti
}

Diabetes Research and Training Center, Department of Medicine, Albert Einstein College of Medicine, Bronx, New York 10461

\begin{abstract}
Intraabdominal adiposity and insulin resistance are risk factors for diabetes mellitus, dyslipidemia, arteriosclerosis, and mortality. Leptin, a fat-derived protein encoded by the $o b$ gene, has been postulated to be a sensor of energy storage in adipose tissue capable of mediating a feedback signal to sites involved in the regulation of energy homeostasis. Here, we provide evidence for specific effects of leptin on fat distribution and in vivo insulin action. Leptin (LEP) or vehicle (CON) was administered by osmotic minipumps for $8 \mathrm{~d}$ to pair-fed adult rats.

During the $8 \mathrm{~d}$ of the study, body weight and total fat mass decreased similarly in LEP and in CON. However, while moderate calorie restriction (CON) resulted in similar decreases in whole body (by $20 \%$ ) and visceral (by 21\%) fat, leptin administration led to a specific and marked decrease (by 62\%) in visceral adiposity. During physiologic hyperinsulinemia (insulin clamp), leptin markedly enhanced insulin action on both inhibition of hepatic glucose production and stimulation of glucose uptake. Finally, leptin exerted complex effects on the hepatic gene expression of key metabolic enzymes and on the intrahepatic partitioning of metabolic fluxes, which are likely to represent a defense against excessive storage of energy in adipose depots. These studies demonstrate novel actions of circulating leptin in the regulation of fat distribution, insulin action, and hepatic gene expression and suggest that it may play a role in the pathophysiology of abdominal obesity and insulin resistance. $(J$. Clin. Invest. 1997. 100:3105-3110.) Key words: obesity • gluconeogenesis $\bullet$ hepatic glucose production • glucose uptake • PEPCK
\end{abstract}

\section{Introduction}

Obesity plays a key role in the pathophysiology of several metabolic and cardiovascular diseases. It has become increasingly evident that the distribution of fat between subcutaneous and visceral sites greatly affects its metabolic impact. Specifically, increased abdominal adiposity has been identified as a major risk factor for diabetes mellitus, dyslipidemia, arteriosclerotic vascular disease, and mortality $(1,2)$.

Address correspondence to Luciano Rossetti, Albert Einstein College of Medicine, 1300 Morris Park Avenue, Bronx, NY 10461. Phone: 718-430-4118/4215; FAX: 718-430-8557; E-mail: Rossetti@ aecom.yu.edu

Received for publication 19 June 1997 and accepted in revised form 17 October 1997.

J. Clin. Invest.

(C) The American Society for Clinical Investigation, Inc. 0021-9738/97/12/3105/06 \$2.00

Volume 100, Number 12, December 1997, 3105-3110

http://www.jci.org
The discovery by positional cloning of the murine obese $(o b)$ gene (3) led to the identification of its product, leptin (LEP), ${ }^{1}$ a $16=\mathrm{kD}$ circulating peptide which is expressed and secreted by adipose cells and is capable of decreasing food intake and increasing thermogenesis (4-7). It has been postulated that leptin functions as a sensor of fat mass and as a hormonal signal which exerts its anorectic effect through its hypothalamic receptor (8-10). Indeed, plasma leptin levels are closely correlated with body weight and fat mass in rodents and humans $(9,11)$.

The recent identification of variants of the $o b$ receptor in several other tissues (12), including liver and adipose tissue (13), and the marked improvements in glucose tolerance after leptin administration to obese animal models (4-7) suggest that leptin may play a more complex role in the regulation of intermediate metabolism than originally recognized. Here we report that leptin plays a unique and novel role in the regulation of fat distribution, in vivo insulin action, and hepatic gene expression.

\section{Methods}

Experimental animals. Three groups of 4-mo-old male Sprague-Dawley rats (Charles River Laboratories, Wilmington, MA) received either saline or recombinant mouse leptin (Amgen, Inc., Thousand Oaks, CA; $>95 \%$ pure by SDS-PAGE) by osmotic minipumps for $8 \mathrm{~d}$ $(n=19)$ : ( $a)$ Ad libidum-fed controls (C-AL); $(b)$ Leptin-treated $(0.5 \pm 0.2 \mathrm{mg} / \mathrm{kg}$ per d) rats (LEP); and (c) Pair-fed controls (C-PF). Food intake and body weight were measured every $24 \mathrm{~h}$ during the 8 -d infusion period. Rats were housed in individual cages and subjected to a standard light $(6: 00$ a.m. to $6: 00$ p.m. $)$-dark $(6: 00$ p.m. to $6: 00$ a.m.) cycle. $1 \mathrm{wk}$ before the in vivo study, rats were anesthetized with an intraperitoneal injection of pentobarbital (50 mg/ $\mathrm{kg}$ body weight) and indwelling catheters were inserted in the right internal jugular vein and in the left carotid artery. The venous catheter was extended to the level of the right atrium and the arterial catheter was advanced to the level of the aortic arch.

Body composition. Body composition was assessed as in reference 14. Rats received an intraarterial bolus injection of $20 \mu \mathrm{Ci}$ of tritiated-labeled water $\left({ }^{3} \mathrm{H}_{2} \mathrm{O}\right.$; New England Nuclear, Boston, MA) and plasma samples were obtained at 30-min intervals for $3 \mathrm{~h}$. Steadystate conditions for plasma ${ }^{3} \mathrm{H}_{2} \mathrm{O}$ specific activity were achieved within $45 \mathrm{~min}$ in all studies. Five plasma samples obtained between 1 and $3 \mathrm{~h}$ were used in the calculation of the whole body distribution space of water. The latter was obtained by dividing the total radioactivity injected (in dpm) by the steady-state specific activity of plasma water (in $\mathrm{dpm} / \mathrm{ml}$ ). Plasma was assumed to be $93 \%$ water. Fat-free mass was calculated as the whole body water distribution space divided by 0.73 and fat mass as the difference of body weight and fatfree mass. Epididymal, perinephric, and mesenteric fat depots were dissected and weighed at the end of each experiment.

Measurements of in vivo glucose kinetics. These measurements were performed as in reference 15 . Briefly, a primed-continuous infu-

1. Abbreviations used in this paper: HGP, hepatic glucose production; LEP, leptin; PEP, phosphoenolpyruvate; PEPCK, PEP carboxykinase. 
sion of HPLC-purified $\left[3-{ }^{3} \mathrm{H}\right]$-glucose $(40 \mu \mathrm{Ci}$ bolus, $0.4 \mu \mathrm{Ci} / \mathrm{min}$; New England Nuclear) was administered for the duration of the study. $2 \mathrm{~h}$ after the basal period, a primed-continuous infusion of somatostatin $(1.2 \mu \mathrm{g} / \mathrm{kg}$ per $\mathrm{min})$ and regular insulin $(3 \mathrm{mU} / \mathrm{kg}$ per min) were administered and a variable infusion of a $25 \%$ glucose solution was started at time zero and periodically adjusted to clamp the plasma glucose concentration at $\sim 7.5 \mathrm{mM}$ for the rest of the studies. Samples for determination of ${ }^{3} \mathrm{H}$-glucose specific activity were obtained at 10-min intervals throughout the infusions.

Glycolysis rates. The rates of glycolysis were estimated as in reference 16. Briefly, plasma-tritiated water specific activity was determined by liquid scintillation counting of the protein-free supernatant (Somogyi filtrate) before and after evaporation to dryness. Since tritium on the $\mathrm{C}-3$ position of glucose is lost to water during glycolysis, it can be assumed that plasma tritium is present either in the form of tritiated water or $\left[3-{ }^{3} \mathrm{H}\right]$-glucose. Regression analysis of the slopes of plasma ${ }^{3} \mathrm{H}_{2} \mathrm{O}$ rate of appearance was performed at 60-min intervals throughout the study. Rates of whole body glycolysis were estimated from the increment per unit time in tritiated water (dpm per $\mathrm{ml}$ per min $) \times$ body water mass $(\mathrm{ml}) /\left[3-{ }^{3} \mathrm{H}\right]$-glucose specific activity $(\mathrm{dpm}$ per $\mathrm{mg}$ ). The rates of glycogen synthesis were estimated as the difference between the rates of glucose uptake and glycolysis. Plasma samples for determination of plasma insulin, glycerol, and FFA concentrations were obtained every $30 \mathrm{~min}$ during the study. The total volume of blood withdrawn was $\sim 3.0 \mathrm{ml} / \mathrm{study}$; to prevent volume depletion and anemia, a solution $(1: 1 \mathrm{vol} / \mathrm{vol})$ of $\sim 3.0 \mathrm{ml}$ of fresh blood (obtained by heart puncture from a littermate of the test ani$\mathrm{mal})$ and heparinized saline $(5 \mathrm{U} / \mathrm{ml})$ was infused.

Hepatic glucose fluxes. Rates of hepatic glucose fluxes were determined as in reference $17.10 \mathrm{~min}$ before the end of the in vivo studies, [U- ${ }^{14} \mathrm{C}$-lactate $(20 \mu \mathrm{Ci}$ bolus, $1.0 \mu \mathrm{Ci} / \mathrm{min}$; New England Nuclear) was administered to determine the contribution of gluconeogenesis to the hepatic glucose-6-phosphate pool. At the end of the infusions, rats were anesthetized (pentobarbital $60 \mathrm{mg} / \mathrm{kg}$ body weight, i.v.), the abdomen was quickly opened, portal vein blood obtained, and liver was freeze-clamped in situ with aluminum tongs precooled in liquid nitrogen. The time from the injection of the anesthetic until freezeclamping of the liver was $<45 \mathrm{~s}$. All tissue samples were stored at $-80^{\circ} \mathrm{C}$ for subsequent analysis. The hepatic ${ }^{14} \mathrm{C}$-phosphoenolpyruvate (PEP) and ${ }^{3} \mathrm{H} /{ }^{14} \mathrm{C}$-UDPglucose sp act were measured and the rates of total flux through glucose-6-phosphatase or total glucose output (TGO), glucose cycling (GC), and PEP-gluconeogenesis (GNG) were calculated. Gluconeogenesis was estimated from the specific activities of ${ }^{14} \mathrm{C}$-labeled hepatic UDPglucose (assumed to reflect the specific activity of hepatic glucose-6-phosphate), and hepatic PEP following the infusion of $\left[\mathrm{U}-{ }^{14} \mathrm{C}\right]$-lactate and $\left[3-{ }^{3} \mathrm{H}\right]$-glucose:

GNG $=$ TGO $\times{ }^{14} \mathrm{C}$-UDP-glucose sp act $/{ }^{14} \mathrm{C}$-PEP sp act $\times 2$.

Net glycogenolysis. Net glycogenolysis was calculated as the difference between HGP and gluconeogenesis. The percentage of the hepatic glucose-6-phosphate pool derived directly from plasma glucose can be calculated as the ratio of ${ }^{3} \mathrm{H}-$ UDPglucose and plasma $\left[{ }^{3} \mathrm{H}-3\right]-$ glucose specific activities. Thus, this ratio also measures the percent contribution of plasma glucose to the glucose-6-phosphatase flux (i.e., glucose cycling). Since total glucose output is equal to the sum of the hepatic glucose production (HGP) plus glucose cycling (and Glucose cycling $={ }^{3} \mathrm{H}-$ UDPG SA/plasma $\left[3-{ }^{3} \mathrm{H}\right]$ glucose sp act $\times$ total glucose output), the equation can be resolved to calculate both glucose cycling (GC) and total glucose output (TGO): TGO $=\mathrm{HGP} /\left(1-{ }^{3} \mathrm{H}-\mathrm{UDPG}\right.$ sp act/plasma. $\left[3-{ }^{3} \mathrm{H}\right]$ glucose sp act) and $\mathrm{GC}={ }^{3} \mathrm{H}-\mathrm{UDPG}$ sp act $/$ plasma $\left[3-{ }^{3} \mathrm{H}\right]$ glucose sp act $\times$ TGO.

Northern blot analyses. Total RNA was isolated with the RNASTAT kit (ISO-TEX Diagnostic, Friendswood, TX). The RNA was transferred to nitrocellulose filter and hybridized with a ${ }^{32} \mathrm{P}$ dCTPlabeled rat GK, Glc-6-Pase, and phosphoenolpyruvate carboxykinase (PEPCK) cDNA probes as in references 18 and 19. The isolated RNA was assessed for purity by the $260 / 280$ ratio absorbency. $20 \mu \mathrm{g}$ of total RNA were electrophoresed on a $1.2 \%$ formaldehyde denatured agarose gel in $1 \times$ Mops running buffer. The RNA was visualized with ethidium bromide and transferred to a hybond-N membrane (Amersham Corp., Arlington Heights, IL). The GK, Glc-6-Pase, and PEPCK cDNA probes were labeled with ${ }^{32} \mathrm{P}$ using the Megaprime labeling system kit (Amersham Corp.). Prehybridization and hybridization were carried out using the rapid hybridization buffer (Amersham Corp.). The filters were then exposed to x-ray films (Fuji Photo Film Co., Tokyo, Japan) for $12-48 \mathrm{~h}$ at $-80^{\circ} \mathrm{C}$ with intensifying screens. Quantification of GK, Glc-6-Pase, and PEPCK mRNA was done by scanning densitometry, normalized for ribosomal RNA signal to correct for loading irregularities.

Analytical procedures. Plasma glucose was measured by the glucose oxidase method (Glucose Analyzer II; Beckman Instruments, Inc., Palo Alto, CA). Plasma insulin was measured by radioimmunoassay, using rat and porcine insulin standards. Plasma leptin (Leptin RIA kit; Linco Research Inc., St. Charles, MO) concentrations were measured by radioimmunoassay. The plasma concentration of free fatty acids was determined by an enzymatic method with an automated kit according to the manufacturer's specifications (Waco Pure Chemical Industries, Osaka, Japan). Plasma $\left[{ }^{3} \mathrm{H}\right]$-glucose radioactivity was measured in duplicates in the supernatants of $\mathrm{Ba}(\mathrm{OH})_{2}$ and $\mathrm{ZnSO}_{4}$ precipitates (Somogyi procedure) of plasma samples (20 $\mu \mathrm{l})$ after evaporation to dryness to eliminate tritiated water. Uridinediphospho-glucose (UDPGlc), uridinediphospho-galactose (UDPgalactose), and phosphoenolpyruvate (PEP) concentrations and specific activities in the liver were obtained through two sequential chromatographic separations, as previously reported.

\section{Results and Discussion}

To examine whether leptin might have effects on the body distribution of fat and in vivo insulin action which are independent of its regulation of food intake and body weight, we administered leptin to an animal model of moderate agedependent obesity, monitored daily food intake, and administered the same amount of food to a group of control animals. Thus, we studied three groups of 4-mo-old (Table I) male Sprague-Dawley (S-D) rats receiving either saline or recombinant mouse leptin by osmotic minipumps for $8 \mathrm{~d}$ : (a) Ad libi-

Table I. Effect of Leptin on Caloric Intake and Body Composition

\begin{tabular}{lccc}
\hline & C-AL & LEP & C-PF \\
\hline Caloric intake (kcal/d) & $72 \pm 3$ & $35 \pm 4^{*}$ & $35 \pm 4^{*}$ \\
BW (grams) & $348 \pm 15$ & $326 \pm 13^{*}$ & $313 \pm 9^{*}$ \\
$\Delta$ BW (grams) & $+10 \pm 5$ & $-25 \pm 3^{*}$ & $-30 \pm 4^{*}$ \\
FFM (grams) & $281 \pm 15$ & $287 \pm 8$ & $271 \pm 11$ \\
Mesenteric fat (grams) & $2.7 \pm 0.5$ & $0.7 \pm 0.2^{\ddagger}$ & $1.3 \pm 0.3^{*}$ \\
Epididymal fat (grams) & $4.6 \pm 0.3$ & $2.1 \pm 0.2^{\ddagger}$ & $3.3 \pm 0.3^{*}$ \\
Perinephric fat (grams) & $1.7 \pm 0.3$ & $0.6 \pm 0.3^{\ddagger}$ & $1.7 \pm 0.3$
\end{tabular}

Osmotic minipumps (model 2ML1; Alzet, Palo Alto, CA) containing either leptin $(2 \mathrm{mg}$ in $2 \mathrm{ml}$ saline) or vehicle were implanted subcutaneously in male Sprague-Dawley rats with initial body weight $(B W)$ of $\sim 340$ grams. Three groups were studied: $(a)$ Ad libidum-fed rats receiving vehicle for $8 \mathrm{~d}(C-A L, n=6)$; (b) Rats receiving leptin for $8 \mathrm{~d}(L E P, n=7)$; (c) Rats pair-fed to match the food intake of the LEP group $(C-P F, n=$ 6). Caloric intake was monitored and adjusted in C-PF, and rats were studied in vivo $8 \mathrm{~d}$ thereafter. Fat-free mass $(F F M)$ was calculated from the whole body volume of distribution of water. ${ }^{*} P<0.001$ vs. C-AL; ${ }^{\ddagger} P<0.001$ vs. C-PF. 

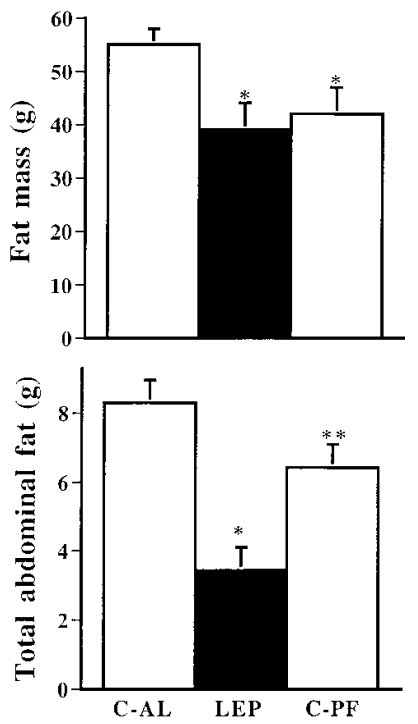

Figure 1. Effect of leptin administration on whole body fat mass and visceral fat. Whole body fat mass was assessed from the body volume of distribution of water and total visceral fat mass represents the sum of mesenteric, epididymal, and perinephric fat depots. In response to the decreased caloric intake, fat mass (top) was similarly decreased in LEP and C-PF compared with C-AL. However, total visceral fat (bottom) was selectively and markedly decreased by $8 \mathrm{~d}$ of leptin administration compared with both C-AL and C-PF. Values represent mean \pm standard error.

dum fed controls (C-AL); (b) Leptin-treated $(0.5 \pm 0.2 \mathrm{mg} / \mathrm{kg}$ per d; plasma leptin concentration $38 \pm 5 \mathrm{ng} / \mathrm{ml}$ ) rats (LEP); and $(c)$ Pair-fed controls (C-PF). Food intake and body weight were measured every $24 \mathrm{~h}$ during the 8 -d infusion period. In accordance with previous studies in rodents (4-7), administration of exogeneous leptin caused a significant decrease in food intake which was on average $50 \%$ lower in LEP than in C-AL. A separate group of sex-, age-, and weight-matched S-D rats were pair-fed (C-PF) to the LEP group. During the $8 \mathrm{~d}$ of the study, body weight increased by $5.7 \%$ in C-AL while it decreased by $8.1 \%$ in LEP and by $9.0 \%$ in C-PF (Table I). Body composition was assessed by the ${ }^{3} \mathrm{H}_{2} \mathrm{O}$ bolus method and by postmortem dissection of fat depots (14). While fat-free mass was not significantly different in any of the experimental groups, the decreases in body weight were accounted for almost exclusively by decreased fat mass in the LEP and C-PF groups (Table I). However, while moderate calorie restriction (C-PF) resulted in similar decreases in total body fat (by 24\%) and visceral fat (by 21\%), leptin administration caused a specific and marked decrease (by $62 \% ; P<0.001$ LEP vs. C-PF) in visceral adiposity (sum of omental, epididymal, and perinephric fat depots) (Fig. 1 and Table I). These results indicate that leptin, in addition to its known effects on food intake and whole body fat mass, has selective actions on visceral or intraabdominal adiposity and is therefore likely to promote a redistribution of body fat. It has been postulated that some of the
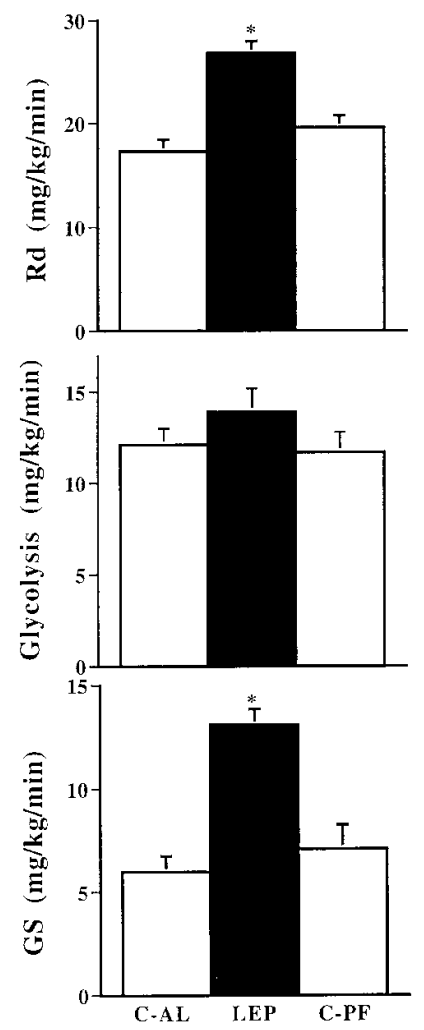

Figure 2. Leptin administration enhances insulin action on peripheral glucose uptake and glycogen synthesis. During insulin clamp studies, the rate of glucose uptake $\left(R_{\mathrm{d}}\right)$ was significantly higher in LEP compared with C-AL and C-PF (top). While the whole body rate of glycolysis (middle) was similar in all groups, the rate of glycogen synthesis $(G S)$ was twofold higher in LEP compared with C-AL and C-PF (bottom).

downstream effects of leptin are mediated via activation of the $\beta_{3}$ adrenoreceptor system (20). Since the administration of selective agonists of the $\beta_{3}$ adrenoreceptor to rodents affects visceral more than subcutaneous adiposity (21), it is likely that the selective effect of leptin on visceral fat is due, in part, to the activation of this neuronal pathway.

Since administration of exogeneous leptin to $o b / o b$ mice markedly improved the associated diabetic state and decreased the plasma insulin concentrations $(5,22)$, we next examined whether leptin improved the in vivo actions of insulin. Indeed, the marked decrease in the plasma insulin concentration in the LEP group compared with both control groups (Table II) suggests that leptin administration may result in improved insulin action in vivo. The two major effects of insulin in vivo are to stimulate the disposal of glucose into peripheral tissues (mostly in skeletal muscle) and to diminish the production of glucose by the liver. Both these actions of insulin can be

Table II. Plasma Concentrations of Glucose, Insulin, FFA, and Glycerol under Postabsorptive Conditions (Basal) and during the Insulin Clamp Studies (Insulin)

\begin{tabular}{|c|c|c|c|c|c|c|}
\hline & \multicolumn{2}{|c|}{ C-AL } & \multicolumn{2}{|c|}{ LEP } & \multicolumn{2}{|c|}{ C-PF } \\
\hline & Basal & Insulin & Basal & Insulin & Basal & Insulin \\
\hline Glucose (mM) & $7.5 \pm 1.1$ & $7.8 \pm 1.2$ & $7.3 \pm 1.2$ & $7.4 \pm 1.0$ & $7.5 \pm 1.1$ & $7.3 \pm 1.1$ \\
\hline Insulin (pM) & $152 \pm 23$ & $408 \pm 18 *$ & $36 \pm 9^{\ddagger}$ & $366 \pm 14 *$ & $76 \pm 5^{\ddagger}$ & $368 \pm 39 *$ \\
\hline FFA (mM) & $1.04 \pm 0.10$ & $0.42 \pm 0.10^{*}$ & $0.85 \pm 0.10$ & $0.38 \pm 0.04 *$ & $0.95 \pm 0.15$ & $0.49 \pm 0.13^{*}$ \\
\hline Glycerol $(\mu \mathrm{M})$ & $98 \pm 4$ & $42 \pm 4^{*}$ & $97 \pm 9$ & $36 \pm 3 *$ & $109 \pm 10$ & $54 \pm 10 *$ \\
\hline
\end{tabular}

The values represent steady-state levels, obtained by averaging five plasma samples during each experimental period. ${ }^{*} P<0.001$ vs. basal; ${ }^{\ddagger} P<0.001$ vs. C-AL. 
estimated in conscious rats using a combination of the insulin (3 $\mathrm{mU} / \mathrm{kg}$ per $\mathrm{min}$ ) clamp and tracer dilution techniques (15, 16). The plasma glucose and insulin concentrations during the insulin clamp studies were similar in the three groups (Table II). The plasma FFA and glycerol concentrations were also similar in the three groups both at baseline and during the insulin infusion (Table II). During physiologic hyperinsulinemia (plasma insulin $\sim 500 \mathrm{pM}$ ), the rate of tissue glucose uptake in LEP $(26.8 \pm 1.1 \mathrm{mg} / \mathrm{kg}$ per $\mathrm{min})$ was 52 and $33 \%$ higher than in C-AL $(17.6 \pm 3 ; P<0.001)$ and C-PF $(20.2 \pm 1.3 ; P<0.001)$, respectively (Fig. 2). This improvement in peripheral insulin action was accounted for by an approximate twofold increase in the rate of glycogen synthesis (LEP vs. C-PF; $P<0.001$ ), while the rate of glycolysis was not significantly increased.

Similarly, leptin markedly enhanced the action of insulin in inhibiting HGP $(1.2 \pm 0.4$ in LEP vs. $5.5 \pm 0.6$ and $4.7 \pm 0.1 \mathrm{mg} /$ $\mathrm{kg}$ per min in C-AL and C-PF, respectively). In a net sense, HGP includes glucosyl units derived from either glycogenolysis or gluconeogenesis and is the net contribution of the liver to circulating glucose. As such it represents the difference between the total flux through the enzyme glucose-6-phosphatase or total glucose output and hepatic glucose cycling. The latter is the portion of phosphorylated glucose (flux through glucokinase) that cycles back into the circulation and under most conditions represents a sensitive index of the activity of these two enzymes. To delineate the mechanism by which leptin enhances insulin action on HGP, we quantitate total glucose output (TGO), glucose cycling (GC) and (PEP)gluconeogenesis $(\mathrm{GNG})$ in the three experimental groups. TGO $(1.7 \pm 0.8$ vs. $7.0 \pm 1.4$ and $6.7 \pm 2.1)$ and $\mathrm{GC}(0.5 \pm 0.2$ vs. $2.7 \pm 0.9$ and $2.7 \pm 1.4 \mathrm{mg} / \mathrm{kg}$ per min) were markedly decreased in LEP vs C-AL and C-PF (Table III, Fig. 3), respectively, indicating that the administration of exogeneous leptin leads to a marked decrease in the flux through glucose-6-phosphatase. In a net sense, the decreased HGP in the LEP group was due to a complete suppression of hepatic glycogenolysis $(0.2 \pm 0.3$ vs. $3.1 \pm 0.9$ and $1.6 \pm 0.3 \mathrm{mg} / \mathrm{kg}$ per min, in LEP vs. C-AL and C-PF, respectively) while the percent contribution of gluconeogenesis to TGO was paradoxically increased (61 \pm 4 vs. $24 \pm 5$ and $44 \pm 4 \%$, in LEP vs. C-AL and C-PF, respectively).

Table III. Relative Contribution of the Direct and Indirect Pathways to the Hepatic Glucose-6-Phosphate Pool

\begin{tabular}{lcccccc}
\hline Group & {$\left[{ }^{14 \mathrm{C}}\right]$ PEP } & {$\left[{ }^{14 \mathrm{C}}\right]$ UDPGlc } & $\begin{array}{c}\text { Indirect } \\
\text { pathway }\end{array}$ & {$\left[{ }^{3} \mathrm{H}\right] \mathrm{Glc}$} & {$\left[{ }^{3} \mathrm{H}\right]$ UDPGlc } & $\begin{array}{c}\text { Direct } \\
\text { pathway }\end{array}$ \\
\hline & \multicolumn{2}{c}{$d p m / n m o l$} & $\%$ & \multicolumn{2}{c}{$d p m / n m o l$} & $\%$ \\
C-AL & $23.2 \pm 4.2$ & $11.1 \pm 2.9$ & $24 \pm 5$ & $34.4 \pm 5.8$ & $12.8 \pm 4.0$ & $37 \pm 9$ \\
LEP & $12.3 \pm 1.3$ & $18.1 \pm 5.6$ & $61 \pm 4^{\ddagger}$ & $22.0 \pm 4.4$ & $7.5 \pm 1.4$ & $35 \pm 6$ \\
C-PF & $18.9 \pm 3.4$ & $15.1 \pm 4.8$ & $44 \pm 4^{*}$ & $38.0 \pm 4.3$ & $15.1 \pm 2.3$ & $39 \pm 6$
\end{tabular}

The specific activities of hepatic uridinediphosphoglucose (UDP-Glc), and phosphoenolpyruvate $(P E P)$ in the liver were obtained through two sequential chromatographic separations, UV detection, and scintillation counting. The percentage of the hepatic glucose-6-phosphate pool derived directly from plasma glucose (Direct pathway) was calculated as the ratio of ${ }^{3} \mathrm{H}$-UDPG and plasma ${ }^{3} \mathrm{H}$-glucose specific activities. The percent of gluconeogenic or indirect contribution (Indirect pathway) was calculated from the specific activities of ${ }^{14} \mathrm{C}$-labeled hepatic UDP-glucose and phosphoenolpyruvate $(P E P) .{ }^{*} P<0.001$ vs. C-AL, ${ }^{\ddagger} P<0.001$ vs. C-AL and C-PF.
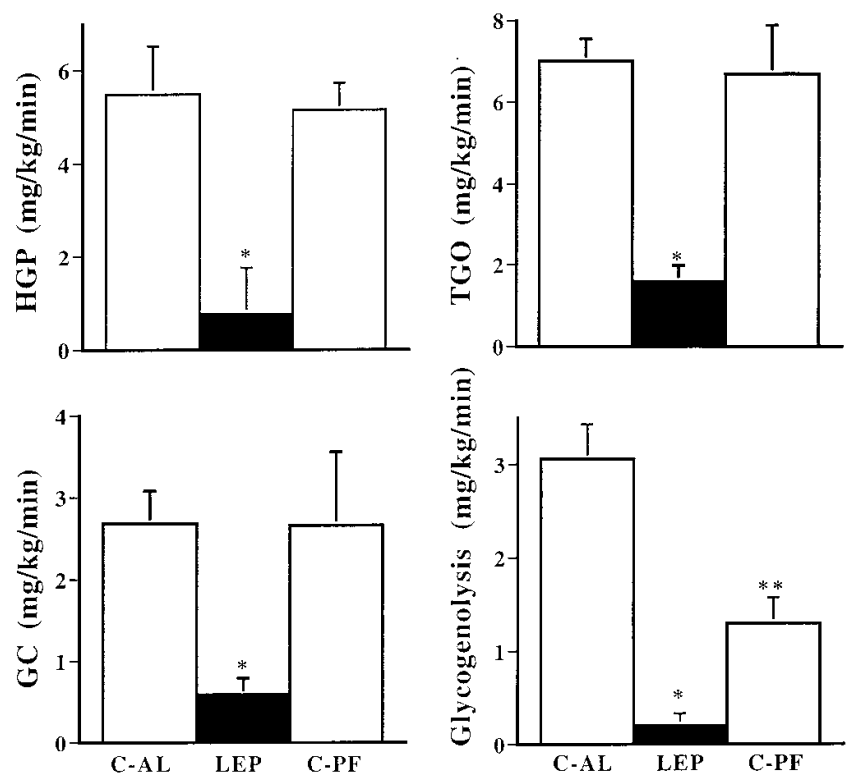

Figure 3. Leptin administration enhances the inhibitory action of insulin on glucose production via complete suppression of hepatic glycogenolysis. During insulin clamp studies, the rate of hepatic glucose production $(H G P)$ was significantly lower in LEP compared with $\mathrm{C}-\mathrm{AL}$ and C-PF. Leptin administration resulted in parallel decreases in the rates of total glucose output $(T G O)$ and glucose cycling $(G C)$, suggesting that the in vivo fluxes through glucokinase and glucose6-phosphatase were both diminished. Since decreased flux through glucose-6-phosphatase may be due to decreased rate of formation of hepatic glucose-6-phosphate, the two major pathways that regulate its pool size, i.e., gluconeogenesis and glycogenolysis, were also measured. While the rate of gluconeogenesis (not shown) was not significantly decreased in LEP, the rate of glycogenolysis was completely blunted in the group receiving leptin for $8 \mathrm{~d}$ compared with both control groups receiving vehicle.

Thus, leptin enhanced the ability of a physiologic increase in the plasma insulin concentration to inhibit glucose production. This effect was due to a striking suppression of hepatic glycogen breakdown leading to diminished flux through glucose-6-phosphatase. Conversely, the flux through gluconeogenesis was preserved. This intrahepatic redistribution of glucose fluxes may serve to diminish the availability of pyruvate for oxidation by limiting intrahepatic glycolysis. This, in turn, would favor the $\beta$-oxidation of long-chain FFA and limit their reesterification to triglycerides (23-27). Taken together the above metabolic data appear to indicate that a prolonged elevation in circulating leptin generates changes in skeletal muscle and liver metabolism aimed to facilitate storage of energy into glycogen and to limit adipose stores. The latter metabolic adaptation may represent a response to the signal generated by leptin in the hypothalamic "lipostat" and/or the results of peripheral actions of the hormone.

Two recent studies have examined the acute effects of pharmacological plasma leptin concentrations during insulin clamp studies $(28,29)$. Sivitz et al. reported a modest increase in the rates of glucose infusion during insulin clamp studies performed in anesthetized rats (28). We have also showed an acute effect of leptin on in vivo insulin action in conscious rats (29). However, in our study labeled glucose was also infused to measure glucose kinetics and thus it was possible to delineate 


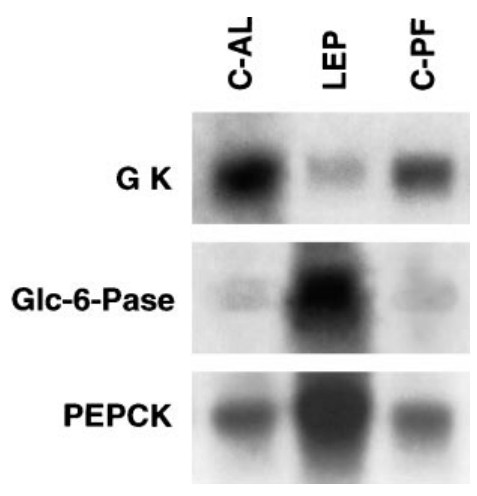

Figure 4. Leptin administration regulates the hepatic gene expression of glucokinase $(G K)$, glucose6-phosphatase (Glc-6-Pase) and phosphoenolpyruvate carboxykinase (PEPCK). Northern analyses of GK, Glc-6-Pase, and PEPCK mRNA was performed in liver freeze-clamped in situ at the completion of the in vivo studies. Total RNA was isolated with the RNA-STAT kit. The RNA was transferred to nitrocellulose filter and hybridized with a ${ }^{32} \mathrm{P}$ dCTP-labeled rat GK, Glc-6-Pase, and PEPCK cDNA probes. $20 \mu \mathrm{g}$ of RNA were used in each lane and equal loading was confirmed by analysis of ethidium-stained ribosomal RNA bands. The figure depicts pooled samples $(n=3 /$ each $)$ from the three experimental groups. Leptin administration resulted in a marked decrease in GK mRNA and increases in both Glc-6-Pase and PEPCK mRNAs.

that leptin did not affect insulin-mediated glucose uptake but rather it improved insulin inhibition of HGP (29).

Leptin administration was also associated with a marked decrease in the hepatic abundance of glucokinase mRNA and with severalfold increases in the hepatic abundance of PEPCK and glucose-6-phosphatase mRNAs (LEP vs. both C-AL and C-PF in Fig. 4). The latter effects of leptin on the hepatic gene expression of key glycolytic and gluconeogenic enzymes is consistent with a recent study in hepatoma cell lines (13). In this study, the inhibitory action of insulin on the gene expression of the gluconeogenic enzyme PEPCK was diminished by leptin. These authors also reported pleiotropic effects of leptin on insulin signaling with decreases in phosphotyrosine phosphorylation of the insulin receptor substrate-1 (IRS-1) and in its interaction with growth factor receptor-bound protein 2 (GRB2), but increases in the phosphorylation of the insulin receptor and in the activity of phosphoinositide-3-kinase associated with IRS-1. These apparently contradictory observations on the relationship between leptin and hepatic insulin signaling may suggest that this peptide has both insulin-like and antiinsulin actions in the liver.

Indeed, in the present study, the effects of prolonged leptin administration on hepatic glucose fluxes and on the gene expression of hepatic enzymes closely resemble the changes induced by fasting. In fact, gluconeogenesis accounted for the majority of glucose output in keeping with the dramatic increase in PEPCK gene expression while overall HGP was paradoxically decreased despite increased gene expression of Glc6-Pase. The decrease in glucose production was accounted for by an almost complete suppression of hepatic glycogenolysis. The biochemical and molecular mechanism(s) for the latter effect remain to be delineated.

In summary, leptin, independent of its effect on food intake (a) selectively decreases visceral fat, $(b)$ enhances the action of insulin on peripheral glucose uptake and hepatic glucose production, $(c)$ modulates the gene expression of key hepatic enzymes, and $(d)$ determines an intrahepatic redistribution of glucose fluxes that resembles that observed with fasting. Our data support the hypothesis that the product of the $o b$ gene plays a pivotal role in the distribution of body adiposity and exerts potent effects on insulin action and on hepatic gene expression. These dramatic metabolic effects in a model of agedependent and moderate obesity suggest that leptin action is an important factor in the pathophysiology of visceral or intraabdominal obesity and insulin resistance. Furthermore, the complex effects of leptin on the intrahepatic partitioning of metabolic fluxes is likely to represent a defense against excessive storage of energy in adipose depots.

\section{Acknowledgments}

We thank Dr. Michael McCaleb (Amgen, Inc., Thousand Oaks, CA) for providing recombinant mouse leptin and Rong Liu, Meizhu Hu, and Robin Squeglia for expert technical assistance.

This work was supported by grants from the National Institutes of Health (NIH: DK 20541, DK 45024, and DK 48321) and by a research grant from Amgen, Inc. Dr. Barzilai is a recipient of the Paul Beeson Physician Faculty Scholar in Aging Award, and is supported by a grant from the NIH (KO8-AG00639). Dr. Hawkins is the recipient of a postdoctoral fellowship from the Medical Research Council of Canada. Dr. Massillon is the recipient of a postdoctoral fellowship from the Juvenile Diabetes Foundation International. Patricia Vuguin is a fellow in the Division of Pediatric Endocrinology.

\section{References}

1. Kissebah, A.H. 1991. Insulin resistance in visceral obesity. Int. J. Obes. 15: (Suppl. 2):109-115.

2. Bjorntorp, P. 1991. Metabolic implications of body fat distribution. Diabetes Care. 14:1132-1143.

3. Zhang, Y., R. Proenca, M. Maffei, M. Barone, L. Leopold, and J. Friedman. 1994. Positional cloning of the mouse obese gene and its human homologue. Nature. 372:425-432.

4. Halaas, JL K. S Gajiwala, M. Maffei, S.L Cohen, B.T Chait, D. Rabinowitz, R.L. Lallone, S.K. Burley, and J.M. Friedman. 1995. Weight-reducing effects of the plasma protein encoded by the obese gene. Science. 269:543546.

5. Pelleymounter, M.A., M.J. Cullen, M.B. Baker, R. Hecht, D. Winters, T. Boone, and F. Collins. 1995. Effects of the obese gene product on body weight regulation in ob/ob mice. Science. 269:540-543.

6. Rentsch, J., N. Levens, and M. Chiesi. 1995. Recombinant ob-gene product reduces food intake in fasted mice. Biochem. Biophys. Res. Commun. 214: $131-136$.

7. Weigle, D.S., T.R. Bukowski, D.C. Foster, S. Holderman, J.M. Kramer, G. Lasser, C.E. Lofton-Day, D.E. Prunkard, C. Raymond, and J.L. Kuijper. 1995. Recombinant ob protein reduces feeding and body weight in the ob/ob mouse. J. Clin. Invest. 96:2065-2070.

8. Campfield, L., F.J. Smith, Y. Guisez, R. Devos, and P. Burn. 1995. Recombinant mouse OB protein: evidence for a peripheral signal linking adiposity and central neural networks. Science. 269:546-549.

9. Frederich, R.C., A. Hamann, S. Anderson, B. Lollmann, B.B. Lowell, and J.S. Flier. 1995. Leptin levels reflect body lipid content in mice: evidence for diet-induced resistance to leptin action. Nat. Med. 1:1311-1314.

10. Schwartz, M.W., R.J. Seeley, L.A. Campfield, P. Burn, and D.G. Baskin. 1996. Identification of targets of leptin action in rat hypothalamus. J. Clin. Invest. 98:1101-1106.

11. Considine, R.V., M.K. Sinha, M.L. Heiman, A. Kriauciunas, T.W. Stephens, M.R. Nyce, J.P. Ohannesian, C.C. Marco, L.J. McKee, T. Bauer, et al. 1996. Serum immunoreactive-leptin concentrations in normal-weight and obese humans. N. Engl. J. Med. 334:324-325.

12. Tartaglia, L., M. Dembski, X. Weng, N. Deng, J. Culpepper, R. Devos, G. Richards, L. Campfield, F. Clark, J. Deeds, et al. 1995. Identification and expression cloning of a leptin receptor, OB-R. Cell. 83:1263-1271.

13. Cohen, B., D. Novick, and M. Rubinstein. 1996. Modulation of insulin activities by leptin. Science. 274:1185-1188.

14. Barzilai, N., D. Massillon, and L. Rossetti. 1995. Effects of fasting on hepatic and peripheral glucose metabolism in conscious rats with near-total fat depletion. Biochem. J. 310:819-826.

15. Rossetti, L., D. Smith, G.I. Shulman, D. Papachristou, and R.A. DeFronzo. 1987. Corrrection of hyperglycemia with phlorizin normalizes tissue sensitivity to insulin in diabetic rats. J. Clin. Invest. 79:1510-1515.

16. Rossetti, L., and A. Giaccari. 1990. Relative contribution of glycogen 
synthesis and glycolysis to insulin-mediated glucose uptake. A dose-response euglycemic clamp study in normal and diabetic rats. J. Clin. Invest. 85:17851792.

17. Rossetti, L., A. Giaccari, N. Barzilai, K. Howard, G. Sebel, and M. Hu. 1993. Mechanism by which hyperglycemia inhibits hepatic glucose production in conscious rats. Implications for the pathophysiology of fasting hyperglycemia in diabetes. J. Clin. Invest. 92:1126-1134.

18. Barzilai, N., and L. Rossetti. 1993. Role of glucokinase and glucose6-phosphatase in the acute and chronic regulation of hepatic glucose fluxes by insulin. J. Biol. Chem. 268:25019-25025.

19. Massillon, D., N. Barzilai, W. Chen, M. Hu, and L. Rossetti. 1996. Glucose regulates in vivo glucose-6-phosphatase gene expression in the liver of diabetic rats. J. Biol. Chem. 271:9871-9874.

20. Mantzoros, C.S., D. Qu, R.C. Frederich, V.S. Susulic, B.B. Lowell, E. Maratos-Flier, and J.S. Flier. 1996. Activation of beta(3) adrenergic receptors suppresses leptin expression and mediates a leptin-independent inhibition of food intake in mice. Diabetes. 45:909-914.

21. Himms-Hagen, J., J. Cui, E.J. Danforth, D J. Taatjes, S.S. Lang, B.L. Waters, and T. Claus. 1994. Effect of CL-316,243, a thermogenic beta 3-agonist, on energy balance and brown and white adipose tissues in rats. Am. J. Physiol. 266:R1371-R1382.

22. Schwartz, M.W., D.G. Baskin, T.R. Bukowski, J.L. Kuijper, D. Foster, G. Lasser, D.E. Prunkard, D.J. Porte, S.C. Woods, R. Seeley, and D. Weigle. 1996. Specificity of leptin action on elevated blood glucose levels and hypotha- lamic neuropeptide Y gene expression in ob/ob mice. Diabetes. 45:531-535.

23. McGarry, J.D., G.P. Mannaerts, and D.W. Foster. 1977. A possible role for malonyl-CoA in the regulation of hepatic fatty acid oxidation and ketogenesis. J. Clin. Invest. 60:265-270.

24. Moir, A.M., and V.A. Zammit. 1993. Rapid switch of hepatic fatty acid metabolism from oxidation to esterification during diurnal feeding of meal-fed rats correlates with changes in the properties of acetyl-CoA carboxylase, but not of carnitine palmitoyltransferase I. Biochem. J. 291:241-246.

25. Prentki, M., and B.E. Corkey. 1996. Are the beta-cell signaling molecules malonyl-CoA and cystolic long-chain acyl-CoA implicated in multiple tissue defects of obesity and NIDDM? Diabetes. 45:273-283.

26. Sidossis, L.S., C.A. Stuart, G.I. Shulman, G.D. Lopaschuk, and R. Wolfe. 1996. Glucose plus insulin regulate fat oxidation by controlling the rate of fatty acid entry into the mitochondria. J. Clin. Invest. 98:2244-2250.

27. Shimabukuro, M., K. Koyama, G. Chen, M.-Y. Wang, F. Trieu, Y. Lee, C.B. Newgard, and R.H. Unger. 1997. Direct antidiabetic effect of leptin through triglyceride depletion of tissues. Proc. Natl. Acad. Sci. USA. 94:46374641.

28. Sivitz, W.I., S.A. Walsh, D.A. Morgan, M.J. Thomas, and W.G. Haynes. 1997. Effects of leptin on insulin sensititvity in normal rats. Endocrinology. 138 3395-3401.

29. Rossetti, L., D. Massillon, N. Barzilai, P. Vuguin, J. Wu, R. Liu, and J. Wang. 1997. Short-term effects of leptin on hepatic gluconeogenesis and in vivo insulin action. J. Biol. Chem. 272:27758-27763. 